\title{
Prevalence of oropharyngeal colonization by Haemophilus influenzae type $b$ in Iranian children
}

A. Karimi, ${ }^{1}$ A. Alborzi, ${ }^{2}$ A. Fahimzad,${ }^{1}$ M. Gooya,${ }^{3}$ A. Esteghamati, ${ }^{4}$ S.H. Armin ${ }^{1}$ and F. Fallah ${ }^{5}$

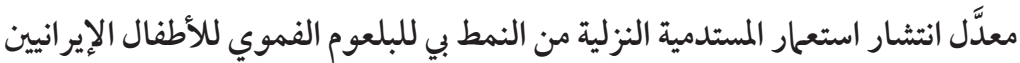

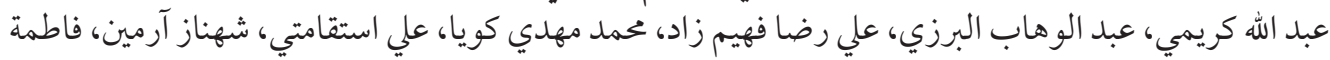

$$
\begin{aligned}
& \text { فلاح }
\end{aligned}
$$

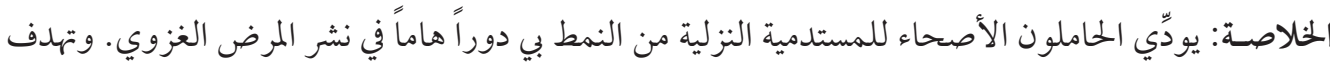

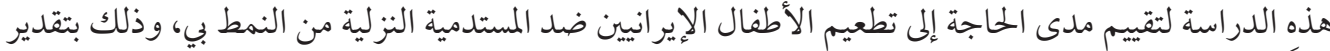

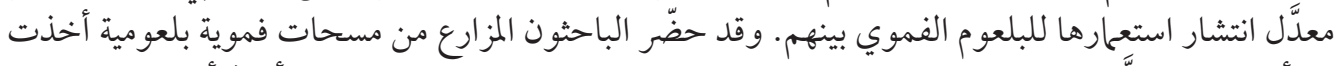

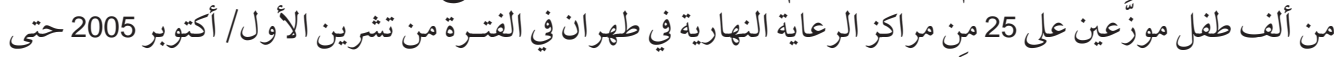

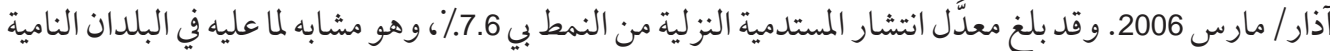

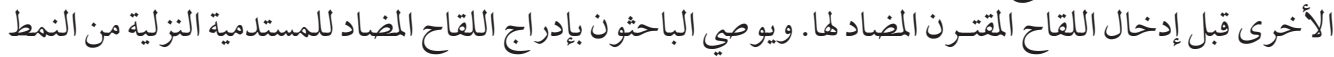

$$
\begin{aligned}
& \text { بي في البرنامج الوطني الإيراني للتمنيع. }
\end{aligned}
$$

ABSTRACT Healthy carriers of Haemophilus influenzae type b (Hib) play an important role in the spread of invasive disease. The aim of this study was to assess the need for Hib vaccination in Iranian children by estimating the prevalence of Hib oropharyngeal colonization among children in Tehran. Cultures were prepared from oropharyngeal swabs of 1000 children in 25 day-care centres in Tehran from October 2005 to March 2006. The prevalence of Hib carriers was 7.6\%, similar to other developing countries prior to inoculation with the conjugate Hib vaccine. We recommend Hib vaccination be included in the Iranian national programme of immunization.

\section{Prévalence de la colonisation oropharyngée par l'Haemophilus influenzae de type b chez les enfants iraniens \\ RÉSUMÉ Les porteurs sains de'Haemophilus influenzae de type b (Hib) jouent un rôle important dans la propagation de la maladie invasive. L'objectif de cette étude était d'évaluer la nécessité d'une vaccination contre le Hib chez les enfants iraniens en estimant la prévalence de la colonisation oropharyngée par le Hib chez les enfants de Téhéran. Des cultures ont été préparées à partir d'échantillons oropharyngés prélevés sur 1000 enfants fréquentant 25 crèches de Téhéran d'octobre 2005 à mars 2006. La prévalence des porteurs de Hib était de 7,6\%, soit un chiffre similaire à celui des autres pays en développement avant l'inoculation par le vaccin Hib conjugué. Nous recommandons l'ajout de la vaccination contre le Hib au programme national de vaccination iranien.}

${ }^{1}$ Department of Paediatric Infectious Diseases, ${ }^{5}$ Department of Microbiology, Faculty of Medicine,

Shaheed Beheshti Medical University, Tehran, Islamic Republic of Iran (Correspondence to A. Fahimzad: safahimzad@yahoo.com).

${ }^{2}$ Department of Paediatric Infectious Diseases, Faculty of Medicine, Shiraz University of Medical Sciences,

Shiraz, Islamic Republic of Iran.

${ }^{3}$ Department of Paediatric Infectious Diseases, Faculty of Medicine, Iran Medical University, Tehran, Islamic

Republic of Iran.

${ }^{4}$ Ministry of Health and Medical Education, Tehran, Islamic Republic of Iran.

Received: 05/09/06; accepted: 28/11/06 


\section{Introduction}

Haemophilus influenzae type b (Hib) is a Gram-negative pleomorphic coccobacilli which can exist in an asymptomatic carrier state or can induce severe invasive diseases such as meningitis, septic arthritis and pneumonia which have a high mortality rate [1]. Oropharyngeal carriage of Hib is important in the transmission, pathogenesis and immunologic response [2].

The availability of conjugated capsular Hib vaccine has dramatically reduced the incidence of Hib-induced diseases in North America [3], Europe [4] and more recently in developing countries such as Brazil [5]. In unvaccinated populations, the invasive diseases caused by Hib particularly affect children under 6 years old $[2,6]$.

There are few studies about the Hib carrier rate in developing countries $[2,7,8]$. This study was done to estimate the Hib carrier rate among children under 6 years old attending day-care centres in Tehran to answer the question whether Hib vaccination is needed in the Islamic Republic of Iran.

\section{Methods}

A total of 25 day-care centres (out of 625) were chosen randomly from different parts of Tehran. All children attending the selected centres were sampled. To select a representative sample, the probability proportional to size sampling technique and simple random cluster sampling technique were used to select the day-care centres. Assuming a frequency of Hib carrier rate of $5 \%$ and $d=2 \%$ the sample size required was estimated to be about 460. Based on the sampling method (cluster sampling) we considered the effect size to be equal to
2. So the final estimated sample size was around 920.

Specimens were collected during the 6 months from October 2005 to March 2006. Parental consent was obtained and a questionnaire with information including age, sex, parents' level education, duration of stay in day-care centre, number of family members and history of recent respiratory tract infection was completed for each child. Children who were ill at the time of the study were excluded.

Oropharyngeal samples were collected with sterile swabs and immediately streaked onto chocolate agar plates. All media were incubated in candle jars with $5 \% \mathrm{CO}_{2}$ at $37^{\circ} \mathrm{C}$ for $24-48$ hours. Suspected colonies were confirmed by Gram staining of smears and their requirement for factors $\mathrm{V}$ and $\mathrm{X}$ for growth (V and $\mathrm{X}$ factor disks from Mast Diagnostics), and then a latex agglutination kit was used to identify Hib (Mast Diagnostics). Gamma-aminolevulinic acid rapid test (Becton, Dickinson Company) was used as a further confirmation test for Hib.

Data were analysed by logistic regression for survey data using Stata/SE, version 8.0. The level of significance was set at $P=0.05$.

\section{Results}

Out of 1000 children from 25 day-care centres who participated, the cultures of 76 $(7.6 \%$, standard error $=0.96)$ were positive for Hib. There were no statistically significant differences in the Hib carrier rate for any demographic characteristic (Table 1) or for other variables, including length of residence in the day-care centre, presence of siblings aged $<5$ years, symptoms of common cold during the previous 1 month and having a smoker in the family (Table 2). 
Table 1 Demographic characteristic of the study children in relation to Haemophilus influenzae type $b$ (Hib) status

\begin{tabular}{|c|c|c|c|c|c|c|c|c|}
\hline \multirow[t]{2}{*}{$\begin{array}{l}\text { Demographic } \\
\text { characteristic }\end{array}$} & \multicolumn{2}{|c|}{$\begin{array}{c}\text { Total } \\
(n=1000)\end{array}$} & \multicolumn{2}{|c|}{$\begin{array}{l}\text { Hib +ve } \\
(n=76)\end{array}$} & \multicolumn{2}{|c|}{$\begin{array}{l}\text { Hib -ve } \\
(n=924)\end{array}$} & \multirow[t]{2}{*}{ OR $(95 \% \mathrm{Cl})$} & \multirow[t]{2}{*}{$P$-value } \\
\hline & No. & $\%$ & No. & $\%$ & No. & $\%$ & & \\
\hline Age (years) & & & & & & & $1.25(0.88-1.87)$ & 0.21 \\
\hline$<2$ & 8 & 0.8 & 0 & 0.0 & 8 & 0.9 & & \\
\hline $2-<4$ & 251 & 25.1 & 16 & 21.1 & 235 & 25.4 & & \\
\hline $4-<6$ & 700 & 70.0 & 57 & 75.0 & 643 & 69.6 & & \\
\hline$\geq 6$ & 41 & 4.1 & 3 & 3.9 & 38 & 4.1 & & \\
\hline Sex & & & & & & & $1.40(0.96-2.03)$ & 0.07 \\
\hline Male & 475 & 47.5 & 34 & 44.7 & 491 & 53.1 & & \\
\hline Female & 525 & 52.5 & 42 & 55.3 & 433 & 46.9 & & \\
\hline Father's education & & & & & & & $0.89(0.50-1.59)$ & 0.66 \\
\hline University & 670 & 67.0 & 53 & 69.7 & 617 & 66.8 & & \\
\hline Diploma & 300 & 30.0 & 21 & 27.6 & 279 & 30.2 & & \\
\hline Below diploma & 30 & 3.0 & 2 & 2.6 & 27 & 3.0 & & \\
\hline Mother's education & & & & & & & $0.95(0.61-1.46)$ & 0.80 \\
\hline University & 584 & 58.4 & 44 & 57.9 & 540 & 58.4 & & \\
\hline Diploma & 382 & 38.2 & 31 & 40.8 & 351 & 38.0 & & \\
\hline Below diploma & 34 & 3.4 & 1 & 1.3 & 33 & 3.6 & & \\
\hline
\end{tabular}

$\mathrm{OR}=$ odds ratio; $\mathrm{Cl}=$ confidence interval .

Table 2 Environmental conditions of the study children in relation to Haemophilus influenzae type $b$ (Hib) status

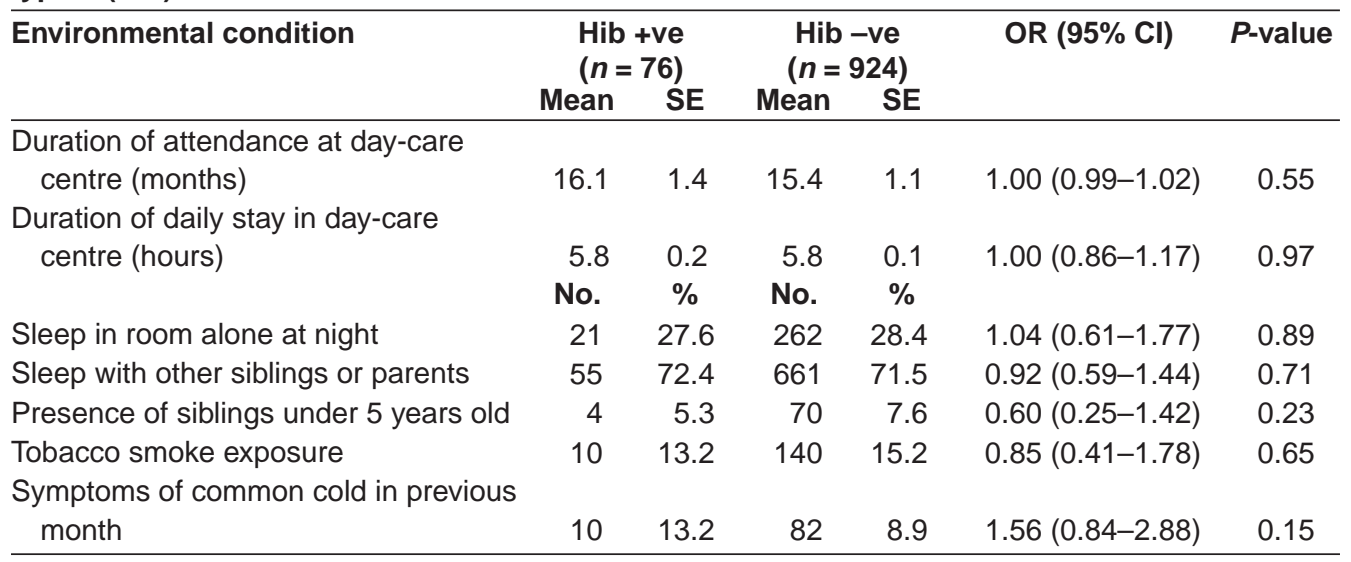

$S E=$ standard error; $O R=$ odds ratio $\mathrm{Cl}=$ confidence interval. 


\section{Discussion}

On the basis of some unpublished Iranian reports of a low incidence of Hib meningitis in children $<5$ years old $(12.5 / 100000)$, we decided to evaluate the Hib carrier rate and answer the question whether we need to initiate Hib vaccination in the Islamic Republic of Iran. Evaluation of the colonization rate in the oropharynx or nasopharynx gives an indication of the possible rate of Hib invasive diseases. One study suggested that oropharyngeal culture for Hib carriers is more sensitive than nasopharyngeal culture [9].

In our study the oropharyngeal Hib carrier rate in the children at day-care centres was $7.6 \%$. This is similar to reports from other developing countries such as the Dominican Republic (7.7\%) [10], Turkey $(9 \%)[11]$, Brazil before vaccination $(7.3 \%)$ [12], as well as remote areas of developed countries such as Alaska $(5 \%-7 \%)[8]$. This prevalence is higher than the Hib colonization rate in some developed countries before vaccination $(2 \%-5 \%)[2,13]$. In these countries the carrier rate has reduced dramatically since vaccination [13].

Two previous studies in the Islamic Republic of Iran showed a low Hib meningitis rate and a high Hib carrier rate, despite an appropriate and reliable method of culturing [unpublished data]. There are some possible explanations for these findings. Antibiotic consumption is high in the Islamic Republic of Iran, and some occult Hib bacteraemia could be prevented by antibiotic therapy before there is induction of invasive diseases such as meningitis. Although the Hib carrier rate cannot be influenced by antibiotic administration [14], early antibiotic consumption can lead to the negative cerebrospinal fluid culture profile of aseptic meningitis [15]. Genetic factors could be another explanation, although there is no evidence that these affect the rate of blood invasion following the carrier state.

Some studies have showed a correlation between Hib colonization and young age $(<2$ years), contact with index cases, day-care centre children and vaccination status $[7,8,16]$. Although there is controversy about the correlation between the Hib carrier rate and other factors, such as sex, number of siblings $<5$ years old and recent respiratory disease [17], our study showed no significant relationship of these variables with the Hib rate. Since it was difficult to take swabs from children $<2$ years old, this was a limitation to our study.

We recommend Hib vaccination be included the Iranian national programme of immunization.

\section{Acknowledgements}

This study was supported by the Paediatric Infectious Research Centre (PIRC) in Mofid Children's Hospital in Tehran. We are grateful to the Iran National Science Foundation (INSF) for financial support.

\section{References}

1. Turk DC. Clinical importance of Haemophilus influenzae. In: Sell SH, Wright PF, eds. Haemophilus influenzae: epidemiology, immunology and prevention of diseases. New York, Elsevier, 1982.

2. Barbour ML. Conjugate vaccines and the carriage of Haemophilus influenzae type b. Emerging infectious diseases, 1996, 2(3):1-9.

3. Liptak GS et al. Decline of pediatric admissions with Haemophilus influenzae type b in New York State, 1982-1993: relation to immunizations. Journal of pediatrics, 1996, 130:923-30.

المجلة الصحية لشرق المتوسط، منظمة الصحة العالمية، المجلد الخامس عشر، العدد ب، 9 +. 
4. Van Alphen $L$ et al. Effect of nationwide vaccination of 3-month-old infants in the Netherlands with conjugate Haemophilus influenzae type b vaccine: high efficacy and lack of herd immunity. Journal of pediatrics, 1997, 131:869-73.

5. Bonifacio da Silva ME, Marin JM. An epidemiological study of Haemophilus influenzae at a Brazilian day care center. Brazilian journal of infectious diseases, 2001, 5(5):260-8.

6. Li KI, Dashefsky B, Wald ER. Haemophilus influenzae type $\mathrm{b}$ colonization in household contacts of infected and colonized children enrolled in day care. Pediatrics, 1986, 78:15-20.

7. Villasenor-Sierra A et al. Prevalencia de estado de portador de Haemophilus influenzae en niños de ciudad Nezahualcóyotl, estado de México [Prevalence of carrier state of Haemophilus influenzae in children of Nezahualcóyotl city, state of Mexico]. Salud pública México, 1996, 38(2):87-93.

8. Galil $\mathrm{K}$ et al. Reemergence of invasive Haemophilus influenzae type $b$ disease in a well-vaccinated population in remote Alaska. Journal of infectious diseases, 1996, 179:101-6.

9. Coen PG, Health PT, Garnet GP. The Hib immunization programme in the Oxford region: an analysis of the impact of vaccine administration on the incidence of disease. Epidemiology and infection, 1999, 123(3):389-402.

10. Gomez E et al. The epidemiology of Haemophilus influenzae type b carriage among infants and young children in
Santo Domingo, Dominican Republic. Pediatric infectious disease journal, 1998, 17:782-6.

11. Bakir M et al. Pharyngeal colonization with Haemophilus influenzae type b among healthy Turkish infants and children. Pediatrics international, 2002, 44:381-6.

12. Bricks LF et al. Oropharyngeal colonization by Haemophilus influenzae in healthy children from Taubaté (São Paulo), prior to the Haemophilus influenzae type B vaccination program in Brazil. Revista do Hospital das Clinicas, 2004, 59(5):23643.

13. Haemophilus influenzae infections. In: Pikering LK, ed. Red book: report of the Committee on Infectious Diseases, 26th ed. Elk Grove Village, Illinois, American Academy of Pediatrics, 2003:293-301.

14. Shapiro ED. Persistent pharyngeal colonization with Haemophilus influenzae type $b$ after intravenous chloramphenicol therapy. Pediatrics, 1981, 67:435-7.

15. Schulkind ML, Altemeier WA III, Ayoub CM. A comparison of ampicillin and chloramphenicol therapy in Hemophilus influenzae meningitis. Pediatrics, 1971, 48:411-6.

16. Murphy TV et al. Pharyngeal colonization with Haemophilus influenzae type b in children in a day care center without invasive disease. Journal of pediatrics, 1985 106:712-6.

17. Michaels $\mathrm{RH}$ et al. Factors affecting pharyngeal Haemophilus influenzae type $b$ colonization rates in children. Journal of clinical microbiology, 1976, 4:413-7. 